\title{
MicroRNA control in the development of systemic autoimmunity
}

Ruozhen Hu and Ryan M O'Connell*

\begin{abstract}
Mammalian immune responses are intended to eradicate microbial pathogens and thus protect individuals from the harmful effects of such infections. However, unresolved inflammation can be devastating to the host and cause tissue damage and organ malfunction. Immune responses can even mistakenly target self-antigens and mediate autoimmune inflammation. Consequently, a variety of cellular and molecular mechanisms have evolved to control the inflammatory responses, and many of these safeguards or triggers are perturbed in the setting of autoimmunity. In this review, we discuss the emerging roles of cellular non-coding RNAs, and in particular microRNAs (miRNAs), in the regulation of autoimmune inflammation. How miRNAs function to impact the onset, magnitude, and resolution of inflammatory responses and recent observations regarding links between miRNAs and specific autoimmune disorders will be addressed. Finally, the diagnostic and therapeutic relevance of miRNAs involved in autoimmunity will be considered. It is clear that, taken together, mammalian miRNAs are integral to the pathogenesis of mammalian autoimmune diseases and may be effective targets of next-generation therapeutics aimed at eradicating tissue inflammation.
\end{abstract}

\section{Introduction}

Autoimmunity was originally described by Paul Ehrlich as 'horror autotoxicus', in which the dysregulated immune system attacks self-tissues [1]. This inappropriate response to one's own tissue antigens can manifest itself in a variety of ways now categorized as distinct types of diseases depending largely upon the tissues and antigens being targeted. At present, many people suffer from at

*Correspondence: ryan.oconnell@path.utah.edu

Division of Microbiology and Immunology, Department of Pathology, University of Utah, 4280 EEJMRB, 15 North Medical Drive East, Salt Lake City, UT 84112, USA least one type of autoimmune disorder that is both debilitating to the person and costly to society. Consequently, there is significant interest in uncovering the molecular mechanisms that regulate the immune system during autoimmunity. Important progress in this area has been made during the past few years as a new class of non-coding RNAs, called microRNAs (miRNAs), has been identified and shown to regulate the immune system during healthy and autoimmune responses [2].

miRNAs are small, single-stranded non-coding RNAs that regulate gene expression by mediating mRNA cleavage, repressing mRNA translation, or causing mRNA destabilization [3]. There are approximately 1,000 predicted miRNAs in the human genome and they are predicted to regulate the expression of approximately $30 \%$ of all human genes [4,5]. Each miRNA potentially targets several hundred mRNAs, leading to inhibition of multiple key targets of various signal pathways. By modulating the expression level of target proteins, miRNAs impact many aspects of mammalian cell biology, including cellular proliferation, differentiation, and apoptosis [6]. Dysregulated miRNA functions have been implicated in many types of human conditions, including cardiovascular diseases, neurological disorders, and cancer, and now are shown to be involved in autoimmunity $[2,3,6,7]$.

The biogenesis of miRNAs has been an intense area of investigation during the past decade, and much has been learned about this process $[3,8]$. miRNAs are encoded by the genome, and the mature miRNA arises from a series of processing steps. They are most commonly transcribed by RNA polymerase II in the form of a primary miRNA (pri-miRNA) transcript that is then cleaved by the endonuclease Drosha into stem-loop precursors (premiRNA) of 60 to 80 nucleotides in length. The premiRNA is next recognized and exported from the nucleus to the cytoplasm by Exportin-5. After additional processing by another RNase III enzyme called Dicer, the premiRNA is converted into a 20- to 22-nucleotide duplex. One strand of the miRNA duplex is subsequently selected and loaded into the RNA-induced silencing complex (RISC), and then the miRNA directs RISC to the 3' untranslated region (UTR) sequence of the target 
mRNAs. The miRNA binds to the 3' UTR with imperfect complementarity, except for the perfect match at the 5' six to eight nucleotides that make up the 'seed' region, and this leads to repressed target gene expression $[3,8]$. This regulation results in an approximately 1.5 - to 4 -fold reduction in target gene protein levels and in many cases has significant biological consequences [2]. Among these physiological roles, miRNAs expressed by cells of the immune system have been shown to impact virtually all aspects of innate and adaptive immune responses [2].

\section{miRNAs regulate mammalian immunity}

Innate immune cells express Toll-like receptors (TLRs), which function as sensors of infectious microbes [9]. Their signaling results in the transcriptional regulation of many immuno-modulatory genes that instruct the ensuing immune response. In addition to protein-coding genes, specific miRNAs that exert either pro- or antiinflammatory effects are upregulated in response to TLR signaling. For example, miR-155 is induced by TLR ligands and contributes to immune cell survival by targeting Src homology-2 domain-containing inositol 5-phosphatase 1 (SHIP1) and suppressor of cytokine signaling 1 (SOCS1). This leads to increased activation of protein kinase B (AKT) and interferon (IFN) response genes $[10,11]$. In contrast, miR-21 is induced by lipopolysaccharide in human peripheral blood mononuclear cells (PBMCs) and results in negative regulation of TLR4 signaling through targeting tumor suppressor programmed cell death protein 4 (PDCD4) [12]. miR146a targets proteins that are involved in the positive transduction of TLR signaling, such as tumor necrosis factor (TNF) receptor-associated factor 6 (TRAF6), and interleukin 1 (IL-1) receptor-associated kinase 1 (IRAK1), and this leads to reduced activation of nuclear factorkappa-B (NF-KB) and production of pro-inflammatory mediators such as IL-6 and TNF- $\alpha[13,14]$. Certain miRNAs are also downregulated in activated innate immune cells. For instance, miR-124 functions in central nervous system (CNS) microglia to prevent activation of microglia and antigen presentation, and its expression is reduced during experimental autoimmune encephalomyelitis (EAE), a mouse disease model of multiple sclerosis (MS) [15].

It is becoming clear that adaptive immune responses against self-tissues are impacted by miRNAs at several distinct points ranging from initial antigen presentation to specific effector mechanisms that are at the heart of tissue damage during autoimmunity (Figure 1). These include (a) activation of antigen-presenting cells $[12,13$, 15-17]. A recent study showed that miR-155 can regulate human dendritic cell development through targeting SOCS1 and Kip1 ubiquitination-promoting complex 1 [16]. (b) Antigen receptor signaling and clonal expansion by lymphocytes are also regulated by miRNAs $[18,19]$. During T-cell development, miR-181a is highly expressed in immature $\mathrm{T}$ cells and promotes T-cell receptor (TCR) signaling and T-cell sensitivity to antigens [18], whereas miR-182 promotes clonal expansion of activated Thelper (Th) lymphocytes in the periphery [19]. (c) Lineage skewing by effector $\mathrm{T}$ lymphocytes is also modulated by miRNAs [17,20-23]. For example, both miR-155 and miR-326 are induced during T-cell activation and their upregulation is critical for proper differentiation of $\mathrm{T}$ cells to Th17 effector cells, which are drivers of tissue inflammation $[17,21,22]$. (d) miRNAs impact the function of $\mathrm{T}$ regulatory $\left(\mathrm{T}_{\text {reg }}\right)$ cells [23]. For example, elevated miR-146a expression in $T_{\text {reg }}$ cells is crucial for their suppressor function on Th1 responses [23]. (e) Effector cytokine production is directly regulated by miRNAs $[24,25]$. Expression of miR-29 in $\mathrm{T}$ cells can suppress IFN- $\gamma$ effector cytokine production by directly targeting the IFN- $\gamma$ mRNA, leading to an impaired immune response to infections [25]. (f) Signaling events that occur in resident tissue cells responding to inflammatory cytokines are influenced by specific miRNAs [26]. A recent study found that miR-23b is expressed by resident fibroblast cells and can suppress activation of NF-kB in response to inflammatory cytokines [26]. Thus, miRNAs can also regulate the crosstalk between cytokines produced by immune cells and cytokine receptor signaling by resident tissue cells during autoimmune disease. (g) Recruitment of additional inflammatory cells through production of factors such as chemokines can also involve miRNAs $[27,28]$. miRNA-125a negatively regulates RANTES (regulated upon activation, normal T-cell expressed, and secreted) expression in activated $\mathrm{T}$ cells in systemic lupus erythematosus (SLE) [27]. Increased miRNA-146a expression negatively regulated the release of the pro-inflammatory chemokines IL-8 and RANTES in human lung alveolar epithelial cells [28]. (h) B-cell class-switching and germinal center formation are also perturbed in the absence of certain miRNAs $[17,29,30]$. Follicular dendritic cells capture immune complexes and activate $B$ cells to produce autoantibodies against selfantigens. In B cells, miR-155 is important for immunoglobulin class-switching by plasma cells and, consequently, miR-155-deficient mice have impaired IgG levels during humoral responses [17,30]. (i) Non-immune cell mechanisms of inflammation are also influenced by miRNAs [31,32]. Upregulation of miR-155 in rheumatoid arthritis synovial fibroblasts (RASFs) was found to repress the levels of matrix metalloproteinase 3 (MMP-3) and reduce the tissue damage [31]. In contrast, upregulation of miR-203 in RASFs elevates levels of MMP-1 and IL-6, which promotes tissue inflammation [32].

In the rest of this review, we will highlight recent findings that have clearly linked immuno-regulatory 


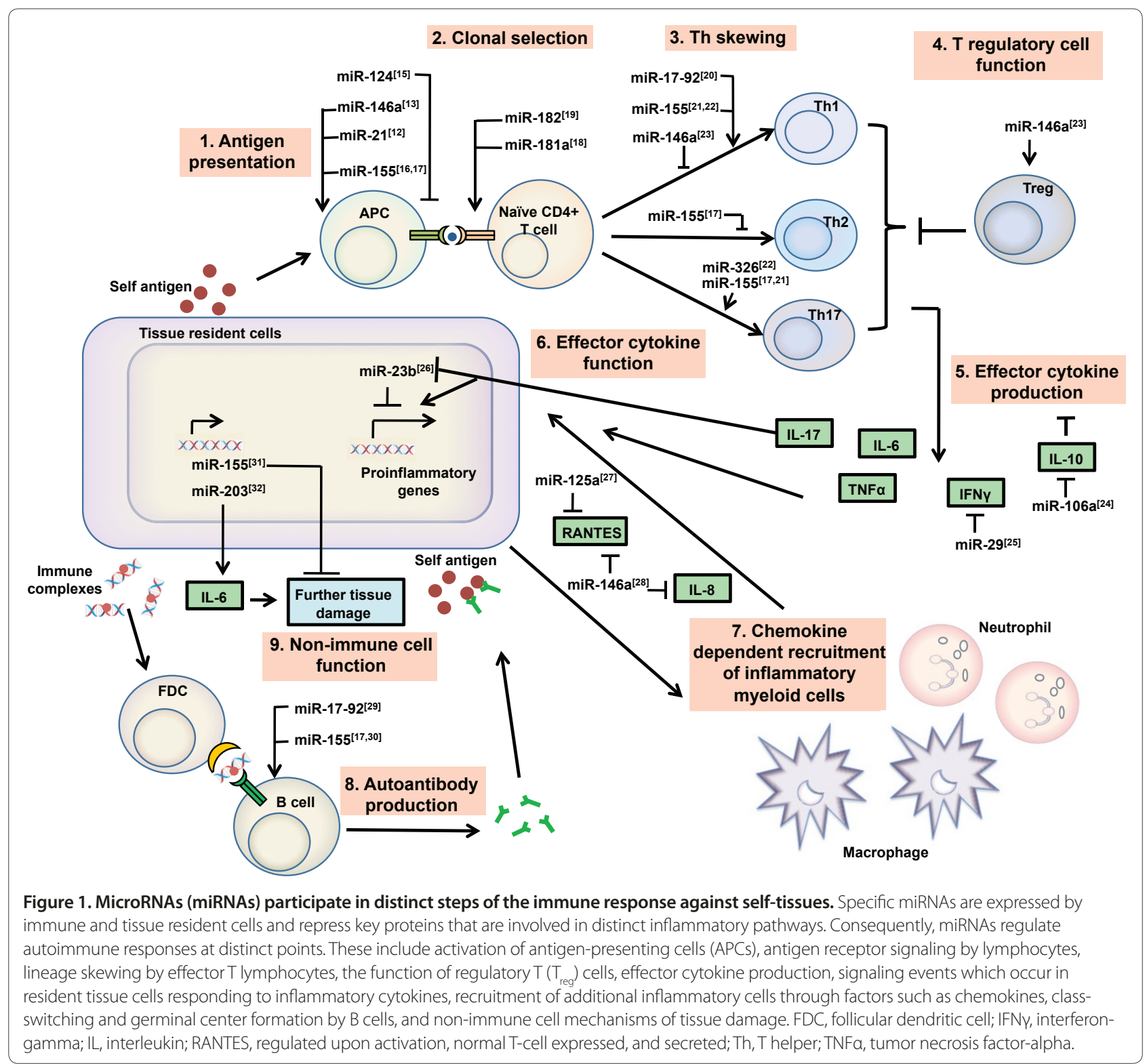

miRNAs to distinct types of autoimmune disorders, both in clinical samples and mouse models of disease, and conclude with our perspective on how this knowledge might be used both diagnostically and therapeutically.

\section{miRNAs and specific types of autoimmune disorders} Rheumatoid arthritis

Rheumatoid arthritis (RA) is a chronic inflammatory disorder that causes bone and joint destruction. Although many protein-coding genes have been implicated in the pathogenesis of RA, our understanding of the molecular mechanisms underlying this disease remains incomplete. Providing new insights into RA, recent studies have shown that critical miRNAs, such as miR-155 and miR146a, are dysregulated in PBMCs and synovial tissues (including fibroblasts) from patients with RA [31-34]. Although the mechanisms leading to the altered miRNA expression are still being determined, it was shown that pro-inflammatory cytokines such as IL- $1 \beta$ and TLR ligands can upregulate miR-155 expression in fibroblasts [31]. In addition to pro-inflammatory agents, epigenetic modification of DNA can modulate expression of RAassociated miRNAs. For example, treatment of cells with the demethylating drug 5-azaC induced miR-203 expression in synovial fibroblasts [32].

The functional consequences of altered miRNA expression in synovial tissues of patients with RA can vary. Upregulation of miR-155 in synovial fibroblasts represses the expression of MMP-3 and MMP-1, which may reduce tissue damage [31]. However, elevated miR-203 in RASFs 
leads to increased secretion of IL-6 and MMP-1, thereby contributing to chronic inflammation and joint destruction during disease [32]. Overexpression of miR-124 in fibroblasts reduced the levels of cyclin-dependent kinase 2 and monocyte chemoattractant protein 1 , consequently decreasing synovial proliferation, angiogenesis, and chemotaxis [35]. These reports indicate that miRNAs regulate a variety of cellular processes involved in RA and that this includes both tissue fibroblasts and the environment. Furthermore, pro-inflammatory cytokines that are usually abundant in patients with RA contribute to altered expression of certain miRNAs that, in turn, exacerbate tissue damage due to inflammation.

Specific miRNAs are also expressed by, and function within, immune cells found in joint tissues of patients with RA. miR-155 is upregulated in RA synovial macrophages and monocytes, whereas miR-146a is increased in RA synovial macrophages [31,33]. Increased miR-155 caused downregulation of SHIP1 in RA-associated monocytes and macrophages, and the upregulation of miR-155 was correlated with enhanced production of pro-inflammatory cytokines such as TNF- $\alpha$ and IL- 6 by these cells [33]. In RA, Li and colleagues [36] also showed that the levels of miR-146a and TNF- $\alpha$ were both elevated. Although TRAF6 and IRAK1 are known targets of miR-146a in other contexts, their expression is not changed in PBMCs of patients with RA when compared with those of healthy controls [34]. Thus, the identification and characterization of additional direct targets of these miRNAs during RA need to be studied further, while this also indicates that miRNA targets can be cell type-specific.

In addition to the analyses of miRNAs in samples of human RA, mouse models of arthritis have been used to identify and test the roles of miRNAs that are involved in RA. In a mouse model of collagen-induced arthritis, miR-155 was critical for the production both Th1 and Th17 cells that contribute to inflammation [33]. In a transfer model of ovalbumin-induced arthritis, inhibition of miR-182 in Th lymphocytes resulted in lower disease severity, indicating an essential contribution of miR-182 to the regulation of Th-cell population expansion in response to self-antigens during disease [19]. Using an autoantibody-mediated arthritis model, Nagata and colleagues [37] showed that injection of double-stranded miR-15a could be taken up by the cells in the synovium and induced cell apoptosis through inhibition of Bcl-2 protein expression. These studies provide further evidence that the dysregulation of miRNAs and thus their functions have consequences during the pathogenesis of RA.

\section{Multiple sclerosis}

MS is driven by dysregulated $\mathrm{T}$ cells that inappropriately respond to myelin and other CNS antigens. The exact mechanisms that initially drive immune dysregulation and inflammation in this setting remain uncertain, as there appears to be a great deal of complexity underlying the triggers of MS. miRNAs are highly expressed in immune cells within CNS lesions of patients with MS, and this is consistent with their emerging roles as regulators of T-cell activation and other mechanisms that cause demyelination during MS.

Dysregulation of miRNA expression has been observed in patients with MS compared with healthy individuals. Studies assessing PBMCs from patients with MS have revealed that miR-18b and miR-599 levels are associated with the time of disease relapse but that miR-96 is involved in disease remission, probably through regulation of cytokine and Wnt signaling [38]. The miRNA expression profiles in $\mathrm{CD}^{+}, \mathrm{CD}^{+}$, and $\mathrm{B}$ cells of relapsing-remitting patients with MS were also studied and once again revealed differential miRNA expression patterns [38]. For example, miR-17-5p was upregulated in $\mathrm{CD} 4^{+}$lymphocytes of patients with MS, whereas miR$15 \mathrm{a}$ and miR16-1 were downregulated in PMBCs from relapsing-remitting patients with MS [39].

EAE is a widely used animal model of MS that is induced by immunizing the mice with myelin antigens such as myelin oligodendrocyte glycoprotein. Recently, this model has been used to study the functional consequence of dysregulated miRNA levels in MS. For instance, both miR-155 and miR-326 are expressed in $\mathrm{CD}^{+} \mathrm{T}$ cells from EAE mice $[21,22]$. These miRNAs regulate the severity of the disease by influencing Th17 development, which is an important driver of tissue inflammation [21,22]. In addition to $\mathrm{T}$ cells, upregulation of miR-326 and miR-155 in active MS lesions is important for the proper macrophage activation [40]. By targeting the 3' UTR of CD47, which functions as an inhibitor of macrophage function, these miRNAs activate macrophages and promote phagocytosis of myelin [40]. The dysregulation of miRNAs in brain-specific macrophages, or microglia, is also found in mouse EAE models. miR-124 is specifically expressed in microglia, but not other peripheral monocytes or macrophages, and leads to their quiescence by targeting the transcription factor C/EBP- $\alpha$ [15]. During the onset of disease, miR-124 is downregulated in microglia, resulting in their activation and contributions to neuroinflammation [15]. These examples demonstrate that miRNAs can regulate the function of both infiltrating lymphocytes, as well as mature resident tissue cells, that participate in the pathogenesis of MS.

\section{Systemic lupus erythematosus}

SLE is an inflammatory disease that is characterized by the presence of autoantibodies against self-antigens and the formation of antibody-immune complexes. Although 
a functional role for miRNAs during SLE has not yet been demonstrated by using mouse models, alterations in miRNA expression levels in PBMCs and kidney biopsies from patients with SLE have been described [41,42]. Among the known miRNAs that play important roles in the immune system, miR-155 and miR-146a were those initially appreciated $[13,14,17,30,43]$. In the context of SLE, their profiles were further studied in patients' urine and serum samples. The level of urinary miR-155 positively correlated with SLE disease activity, whereas the level of urinary miR-146a inversely correlated with the urinary expression of TNF- $\alpha$ [44]. These studies support the possibility that miRNA expression profiles, even in extracellular fluids, may be used as diagnostic markers of disease type and severity.

The functional targets of miRNAs that become dysregulated during SLE are beginning to be studied. Tang and colleagues [45] found that miR-146a expression was downregulated in PBMCs from patients with SLE and that miR-146a negatively regulated the type I IFN pathway by targeting IFN regulatory factor-5, signal transducer and activator of transcription 1 (STAT1), and TRAF6/IRAK-1, key regulators of the type I IFN pathway. The authors also reported that the downregulation of miR-146a negatively correlated with disease activity in patients with SLE. These results indicate that downregulation of miR-146a may contribute to the elevated production of IFN $\alpha$ observed in SLE, which itself plays a pivotal role in the pathogenesis of the disease [45]. Another miRNA, miR-125a, has reduced expression in PBMCs from patients with SLE and contributes to T-cell activation in patients with lupus by targeting KLF13 [27]. The increased expression of KLF13 results in overexpression of the inflammatory chemokine RANTES (CCL5). This triggers the detrimental effects of infiltrating inflammatory mediators [27]. miR-21 and miR-148 are also overexpressed in PBMCs of patients with SLE, and these miRNAs target the DNA-methylation pathway. This causes DNA hypomethylation and overexpression of autoimmune-associated genes that are methylationsensitive, thus promoting autoimmune responses associated with SLE [46]. These examples clearly link miRNAs to SLE and indicate that it is important to identify specific targets of SLE-associated miRNAs in order to understand how these non-coding RNAs influence disease pathogenesis.

The molecular mechanisms that cause dysregulation of miRNA expression during SLE are still being investigated. One possible mechanism could involve polymorphisms in the promoter regions of miRNAs that can affect miRNA transcription. Through genome-wide association studies, two genetic variants that are located in the promoter region of miR-146a, called rs57095329 and rs2431697, were found and they are associated with SLE susceptibility in Chinese and European patients, respectively $[47,48]$. Through reduced binding affinity of transcription factors to this region (for example, Ets-1), miR-146a expression was reduced [47]. Because miR146a plays an established anti-inflammatory role, its diminished expression could lead to enhanced expression of its target genes involved in signaling pathways that drive SLE. These are among several aspects of SLE that need to be investigated in greater detail.

\section{Inflammatory bowel disease}

Inflammatory bowel disease (IBD), including Crohn's disease (CD) and ulcerative colitis (UC), is a chronic inflammatory disorder of the large or small intestines or both. The differential expression of circulating miRNAs has been studied in the sera of patients with pediatric CD and in peripheral blood samples of patients with $C D$ or UC [49,50]. Different peripheral blood miRNA expression signatures were observed between distinct experimental groups. For example, patients with active CD exhibited a different miRNA signature than patients with active UC when compared with healthy controls [49]. In another study, analysis of miRNAs revealed a unique pattern of differentially expressed miRNAs in platelets from patients with IBD [50]. Notably, through a genomewide analysis, hsa-miR-941 was shown to be physically linked to UC susceptibility loci, suggesting a potential role of miRNAs in the pathogenesis of disease [50].

Epithelial cell miRNAs were shown to be key regulators of gut mucosal immunity and function by influencing the crosstalk between the epithelium and $\mathrm{T}$ cells which is important for promoting protective T helper type 2 (Th2) responses [51]. Recently, unique miRNA expression profiles have also been observed in epithelial cells of patients with different types of IBD [52-54]. miRNAs are differentially expressed in active UC and CD tissues when compared with healthy control samples, suggesting that miRNA expression is specific to the degree of inflammation as well as location and type of disease [52]. miRNA dysregulation in non-inflamed CD and UC tissues has also been reported. The pattern of miRNA expression in both non-inflamed CD and UC tissues has overlap when compared with inflamed tissues, suggesting that the altered miRNA expression patterns in the non-inflamed tissues of patients with IBD may be used as new diagnostic biomarkers [53]. Furthermore, miR-31 expression was found to be increased during disease progression in patients with IBD [54]. Together, these data indicate that specific miRNAs provide new markers that can be used to discriminate between distinct disease types in patients with IBD.

\section{Sjögren's syndrome}

Sjögren's syndrome (SS) is a chronic autoimmune disease defined by an impaired immune system that targets 
moisture-producing glands, such as lachrymal and salivary glands, leading to clinical symptoms that include dry eyes and a dry mouth. Although studies addressing the role of miRNAs in SS have just begun, dysregulation of certain miRNAs, such as miR-155 and miR-146a, has been observed in both salivary glands and PBMCs from patients with SS [55-57]. For instance, miR-146a is significantly increased in salivary glands and PBMCs of patients with SS [55]. The upregulation of miR-146a in PBMCs of patients with SS was associated with the dysregulation of its target gene IRAK1 [55]. Another example of dysregulated miRNAs in patients with SS is the miR-17-92 cluster. miRNAs produced from miR-17-92 have been associated with lymphocytic pathologies [58], indicating that they may play a role in the pathogenesis of SS [57].

miRNA expression patterns were also studied in saliva exosomes isolated from patients with SS, in which distinct miRNAs were found. This innovative approach might provide a diagnostic method for characterizing this disease without the need for invasive collection of biopsies [56]. Furthermore, next-generation sequencing of the small RNA populations in minor salivary glands of patients with SS revealed several previously unidentified miRNAs that are associated with SS [59]. These data suggest that miRNAs are involved in SS pathogenesis and may serve as useful diagnostic markers of disease type and severity. However, the functional roles of miRNAs associated with SS need to be tested to determine whether therapeutic targeting of miRNAs is a possible option for patients with SS.

\section{Psoriasis}

Psoriasis (PS) is a systemic and chronic inflammatory disease that causes skin redness and irritation. The mechanisms responsible for the dysregulation of the immune system during PS are not fully understood, and several studies have pointed to the involvement of miRNAs in the pathogenesis of PS [60,61]. miR-203, miR-21, and miR-146a are all increased whereas miR-125b is downregulated in PS compared with healthy skin [60]. This suggests that miRNAs may play a role in PS pathogenesis. Increased miR-203 levels in PS are associated with constitutive activation of STAT3 signaling, and this is achieved by direct targeting of SOCS3 for repression [60]. This, in turn, leads to infiltration of immune cells to the skin of patients with PS. In another recent study, miR-21 was shown to be upregulated in both dermal $\mathrm{T}$ lymphocytes and epidermal cells of PS versus healthy skin [61]. Furthermore, this study revealed that a function of miR-21 in activated T cells is to enhance the survival of activated $\mathrm{T}$ cells, consequently promoting psoriatic skin inflammation [61].

\section{Primary biliary cirrhosis}

Primary biliary cirrhosis $(\mathrm{PBC})$ is an autoimmune disease that is defined by the destruction of small bile ducts within the liver. Differentially expressed miRNAs have been identified in the livers of patients with $\mathrm{PBC}$ compared with normal controls $[62,63]$. miR-299-5p, miR328, and miR-371 are upregulated in patients with PBC, whereas miR-26a, miR-122a, and miR-99a are downregulated [62]. In this first study to describe altered expression of hepatic miRNA in patients with $\mathrm{PBC}$, the authors also showed mRNA targets that may be affected by this particular miRNA expression signature, thus providing information for the underlying molecular mechanism that is important for the pathogenesis of $\mathrm{PBC}$ [62]. However, additional studies are required to demonstrate a causal link between these miRNAs, their targets, and the development of PBC. In another report, miR-506 expression was found to be increased in $\mathrm{PBC}$ liver specimens when compared with normal livers [63]. Interestingly, mouse studies have shown that one of the miR-506 predicted targets, $\mathrm{Cl}^{-} / \mathrm{HCO}^{-}$anion exchanger 2 (AE2), is involved in the pathogenesis of PBC. This report demonstrated that elevated miR-506 expression led to reduced AE2 levels and defective biliary secretory activity and did so by directly repressing AE2 protein expression through a 3' UTR-dependent mechanism [63]. These data indicate that miR-506 may function as a potential therapeutic target to treat $\mathrm{PBC}$.

\section{Diabetes}

Type 1 diabetes (T1D) is an autoimmune disease that is characterized by the production of autoantibodies that target the pancreatic beta cells, which are the major insulin-secreting cells. The miRNA expression profile was assessed for both immune cells and pancreatic beta cells of patients with T1D [64-67]. In $\mathrm{T}_{\text {reg }}$ cells of patients with diabetes, miR-510 expression is increased whereas miR-342 and miR-191 are decreased [64]. miR-326 expression is increased in peripheral blood lymphocytes from patients with T1D and increased expression of this miRNA is highly correlated with disease severity [65]. In pancreatic beta cells, NF-kB-dependent miR-21 expression results in decreased levels of the tumor suppressor PDCD4. This leads to resistance to apoptosis and reduced tissue damage [66]. In a mouse study in which T1D is induced by streptozotocin, a Dicer deficiency in pancreatic islet cells enhanced disease severity, indicating that miRNAs expressed in islet beta cells play protective roles during T1D [67].

\section{miRNAs as biomarkers and therapeutic targets}

Overall, the importance of proper miRNA expression and function during the onset, progression, and resolution of different types of autoimmune diseases is 
becoming clear. Dysregulated miRNA expression contributes to many aspects of autoimmunity by acting in immune and tissue resident cells and by impacting the crosstalk between these compartments. Through repression of their targets, many of which are positive or negative regulators of important cellular processes, miRNAs influence a variety of signaling pathways with established roles in autoimmunity. Some miRNAs target the same signaling pathway in different types of autoimmune diseases. For example, miR-146a targets TRAF6/ IRAK-1 in both SLE and SS [45,55], whereas miR-21 targets PDCD4 in both SLE and T1D [66,68]. In addition, by targeting the same mRNA, miRNAs play distinct roles in different type of diseases. For instance, by repressing PDCD4, miR-21 promotes autoimmunity in patients with SLE but reduces tissue damage in patients with T1D $[66,68]$. In contrast, other miRNAs target distinct signaling pathways. miR-21 targets the DNA-methylation pathway, tumor suppressor PDCD4, or T-cell apoptosis to promote autoimmune responses in SLE and PS $[46,61,68]$. These studies suggest that miRNAs have multiple targets during autoimmune diseases and that, by affecting different signaling pathways, miRNAs contribute either positively or negatively to autoimmune conditions. Owing to the multi-target nature of miRNA biology, it remains challenging to quantitatively assess the relative contribution of individual targets to miRNAdependent phenotypes, and this should be a goal of future approaches.

Now that a causal relationship between specific miRNAs and autoimmune pathologies has been established in mouse models, the next important step will be the development of therapies that can exploit these connections clinically. As shown in Figure 1, therapies could be designed to target specific steps in the inflammatory process or used in combination to achieve a potentially stronger effect. Among the approaches that have been effective in preclinical mouse models are the use of chemically stabilized anti-sense inhibitors, as demonstrated by targeting of miR-155 or miR-182a [19,69], or delivery of such inhibitors via nanoparticles, as has been shown for miR-155 [70]. One of the most successful miRNA-based therapeutic applications is systemic administration of a miR-122 antagonist, SPC3649. This agent, which is in phase 2 clinical trials, is delivered to hepatocytes to block replication of hepatitis $C$ viruses [71]. Other miRNA-based therapeutics against different types of human diseases are under preclinical development, including miRNA antagonists to prevent or reverse chronic heart failure and myocardial infarction [72] in addition to miRNA replacement for cancer treatment [73]. Although these are important advances, consideration should also be given to the development of methods that target specific types of cells responsible for driving disease phenotypes. Among the benefits of such a technology would be the avoidance of repressing miRNAs expressed by bystander cell types in vivo, which could cause unintended side effects.

Although therapeutic approaches involving miRNAs are emerging, these will take time to develop into agents that are used routinely in the clinic. Thus, a more immediate application of understanding the link between miRNAs and autoimmunity will be in the arena of diagnostics. Many of the above studies provide strong evidence that miRNAs can be used as diagnostic and prognostic biomarkers, not only for disease classification but also to define disease severity and predict future outcome. As we continue to grasp which miRNAs are perturbed in specific types and stages of defined autoimmune subtypes, such strategies will grow increasingly useful in the clinic.

This article is part of the series on Epigenetics and rheumatic diseases, edited by Nan Shen. Other articles in this series can be found at http://arthritis-research.com/series/epigenetics

\section{Abbreviations}

AE2, $\mathrm{Cl}^{-} / \mathrm{HCO}^{-}$anion exchanger 2; CD, Crohn's disease; CNS, central nervous system; EAE, experimental autoimmune encephalomyelitis; IBD, inflammatory bowel disease; IFN, interferon; IL, interleukin; IRAK1, interleukin-1 receptorassociated kinase 1; miRNA, microRNA; MMP, matrix metalloproteinase; MS, multiple sclerosis; NF-kB, nuclear factor-kappa-B; PBC, primary biliary cirrhosis; PBMC, peripheral blood mononuclear cell; PDCD4, programmed cell death protein 4; pre-miRNA, precursor miRNA; PS, psoriasis; RA, rheumatoid arthritis; RANTES, regulated upon activation, normal T-cell expressed, and secreted; RASF, rheumatoid arthritis synovial fibroblast; RISC, RNA-induced silencing complex; SHIP1, Src homology-2 domain-containing inositol 5-phosphatase 1 SLE, systemic lupus erythematosus; SOCS1, suppressor of cytokine signaling 1 ; SS, Sjögren's syndrome; STAT, signal transducer and activator of transcription; T1D, type 1 diabetes; Th, Thelper; TLR, Toll-like receptor; TNF, tumor necrosis factor; TRAF6, tumor necrosis factor receptor-associated factor $6 ; T_{\text {reg' }}$ regulatory T; UC, ulcerative colitis; UTR, untranslated region.

\section{Competing interests}

The authors declare that they have no competing interests.

\section{Acknowledgments}

We would like to thank members of the lab for editing this review and Noah Welker for assisting with the figure preparation.

Published: 25 January 2013

\section{References}

1. Mackay IR: Travels and travails of autoimmunity: a historical journey from discovery to rediscovery. Autoimmun Rev 2010, 9:A251-258.

2. O'Connell RM, Rao DS, Chaudhuri AA, Baltimore D: Physiological and pathological roles for microRNAs in the immune system. Nat Rev Immunol 2010, 10:111-122.

3. Filipowicz W, Bhattacharyya SN, Sonenberg N: Mechanisms of posttranscriptional regulation by microRNAs: are the answers in sight? Nat Rev Genet 2008, 9:102-114.

4. Berezikov E, Guryev V, van de Belt J, Wienholds E, Plasterk RH, Cuppen E: Phylogenetic shadowing and computational identification of human microRNA genes. Cell 2005, 120:21-24.

5. Lewis BP, Burge CB, Bartel DP: Conserved seed pairing, often flanked by adenosines, indicates that thousands of human genes are microRNA targets. Cell 2005, 120:15-20.

6. Bartel DP: MicroRNAs: target recognition and regulatory functions. Cell 
2009, 136:215-233

7. Ha TY: MicroRNAs in human diseases: from cancer to cardiovascular disease. Immune Netw 2011, 11:135-154.

8. Kim VN: MicroRNA biogenesis: coordinated cropping and dicing. Nat ReV Mol Cell Biol 2005, 6:376-385.

9. Janeway CA Jr., Travers P, Walport M, Schlomchik MJ: Signaling through immune system receptors. In Immunobiology: The Immune System in Health and Disease. New York: Garland Science; 2005:203-236.

10. O'Connell RM, Chaudhuri AA, Rao DS, Baltimore D: Inositol phosphatase SHIP1 is a primary target of miR-155. Proc Natl Acad Sci U S A 2009, 106:7113-7118.

11. Wang P, Hou J, Lin L, Wang C, Liu X, Li D, Ma F, Wang Z, Cao X: Inducible microRNA-155 feedback promotes type I IFN signaling in antiviral innate immunity by targeting suppressor of cytokine signaling 1. J Immunol 2010, 185:6226-6233

12. Sheedy FJ, Palsson-McDermott E, Hennessy EJ, Martin C, O'Leary JJ, Ruan Q, Johnson DS, Chen Y, O'Neill LA: Negative regulation of TLR4 via targeting of the proinflammatory tumor suppressor PDCD4 by the microRNA miR-21. Nat Immunol 2010, 11:141-147.

13. Boldin MP, Taganov KD, Rao DS, Yang L, Zhao JL, Kalwani M, Garcia-Flores Y, Luong M, Devrekanli A, Xu J, Sun G, Tay J, Linsley PS, Baltimore D: miR-146a is a significant brake on autoimmunity, myeloproliferation, and cancer in mice. J Exp Med 2011, 208:1189-1201.

14. Taganov KD, Boldin MP, Chang KJ, Baltimore D: NF-kappaB-dependent induction of microRNA miR-146, an inhibitor targeted to signaling proteins of innate immune responses. Proc Natl Acad Sci U S A 2006, 103:12481-12486

15. Ponomarev ED, Veremeyko T, Barteneva N, Krichevsky AM, Weiner HL: MicroRNA-124 promotes microglia quiescence and suppresses EAE by deactivating macrophages via the C/EBP-alpha-PU.1 pathway. Nat Med 2011, 17:64-70.

16. Lu C, Huang X, Zhang X, Roensch K, Cao Q, Nakayama Kl, Blazar BR, Zeng Y, Zhou X: miR-221 and miR-155 regulate human dendritic cell development, apoptosis, and IL-12 production through targeting of p27kip1, KPC1, and SOCS-1. Blood 2011, 117:4293-4303.

17. Rodriguez A, Vigorito E, Clare S, Warren MV, Couttet P, Soond DR, van Dongen S, Grocock RJ, Das PP, Miska EA, Vetrie D, Okkenhaug K, Enright AJ, Dougan G, Turner M, Bradley A: Requirement of bic/microRNA-155 for normal immune function. Science 2007, 316:608-611

18. Li QJ, Chau J, Ebert PJ, Sylvester G, Min H, Liu G, Braich R, Manoharan M, Soutschek J, Skare P, Klein LO, Davis MM, Chen CZ: miR-181a is an intrinsic modulator of T cell sensitivity and selection. Cell 2007, 129:147-161.

19. Stittrich AB, Haftmann C, Sgouroudis E, Kühl AA, Hegazy AN, Panse I, Riedel R, Flossdorf M, Dong J, Fuhrmann F, Heinz GA, Fang Z, Li N, Bissels U, Hatam F, Jahn A, Hammoud B, Matz M, Schulze FM, Baumgrass R, Bosio A, Mollenkopf HJ, Grün J, Thiel A, Chen W, Höfer T, Loddenkemper C, Löhning M, Chang HD, Rajewsky N, Radbruch A, Mashreghi MF: The microRNA miR-182 is induced by IL-2 and promotes clonal expansion of activated helper T lymphocytes. Nat Immunol 2010, 11:1057-1062.

20. Sasaki K, Kohanbash G, Hoji A, Ueda R, McDonald HA, Reinhart TA, Martinson J, Lotze MT, Marincola FM, Wang E, Fujita M, Okada H: miR-17-92 expression in differentiated T cells - implications for cancer immunotherapy. J Trans/ Med 2010, 8:17.

21. O'Connell RM, Kahn D, Gibson WS, Round JL, Scholz RL, Chaudhuri AA, Kahn ME, Rao DS, Baltimore D: MicroRNA-155 promotes autoimmune inflammation by enhancing inflammatory T cell development. Immunity 2010, 33:607-619.

22. Du C, Liu C, Kang J, Zhao G, Ye Z, Huang S, Li Z, Wu Z, Pei G: MicroRNA miR-326 regulates $\mathrm{TH}-17$ differentiation and is associated with the pathogenesis of multiple sclerosis. Nat Immuno/ 2009, 10:1252-1259.

23. Lu LF, Boldin MP, Chaudhry A, Lin LL, Taganov KD, Hanada T, Yoshimura A, Baltimore D, Rudensky AY: Function of miR-146a in controlling Treg cellmediated regulation of Th1 responses. Cell 2010, 142:914-929.

24. Sharma A, Kumar M, Aich J, Hariharan M, Brahmachari SK, Agrawal A, Ghosh $B$ : Posttranscriptional regulation of interleukin- 10 expression by hsa-miR106a. Proc Natl Acad Sci USA 2009, 106:5761-5766.

25. Ma F, Xu S, Liu X, Zhang Q, Xu X, Liu M, Hua M, Li N, Yao H, Cao X: The microRNA miR-29 controls innate and adaptive immune responses to intracellular bacterial infection by targeting interferon-gamma. Nat Immunol 2011, 12:861-869

26. Zhu S, Pan W, Song X, Liu Y, Shao X, Tang Y, Liang D, He D, Wang H, Liu W, Shi
Y, Harley JB, Shen N, Qian Y: The microRNA miR-23b suppresses IL-17associated autoimmune inflammation by targeting TAB2, TAB3 and IKKalpha. Nat Med 2012, 18:1077-1086.

27. Zhao X, Tang Y, Qu B, Cui H, Wang S, Wang L, Luo X, Huang X, Li J, Chen S, Shen N: MicroRNA-125a contributes to elevated inflammatory chemokine RANTES levels via targeting KLF13 in systemic lupus erythematosus. Arthritis Rheum 2010, 62:3425-3435.

28. Perry MM, Moschos SA, Williams AE, Shepherd NJ, Larner-Svensson HM, Lindsay MA: Rapid changes in microRNA-146a expression negatively regulate the IL-1beta-induced inflammatory response in human lung alveolar epithelial cells. J Immuno/ 2008, 180:5689-5698.

29. Mendell JT: miRiad roles for the miR-17-92 cluster in development and disease. Cell 2008, 133:217-222

30. Vigorito E, Perks KL, Abreu-Goodger C, Bunting S, Xiang Z, Kohlhaas S, Das PP Miska EA, Rodriguez A, Bradley A, Smith KG, Rada C, Enright AJ, Toellner KM, Maclennan IC, Turner M: microRNA-155 regulates the generation of immunoglobulin class-switched plasma cells. Immunity 2007, 27:847-859.

31. Stanczyk J, Pedrioli DM, Brentano F, Sanchez-Pernaute O, Kolling C, Gay RE, Detmar M, Gay S, Kyburz D: Altered expression of MicroRNA in synovial fibroblasts and synovial tissue in rheumatoid arthritis. Arthritis Rheum 2008, 58:1001-1009.

32. StanczykJ, Ospelt C, Karouzakis E, Filer A, Raza K, Kolling C, Gay R, Buckley CD, Tak PP, Gay S, Kyburz D: Altered expression of microRNA-203 in rheumatoid arthritis synovial fibroblasts and its role in fibroblast activation. Arthritis Rheum 2011, 63:373-381.

33. Kurowska-Stolarska M, Alivernini S, Ballantine LE, Asquith DL, Millar NL, Gilchrist DS, Reilly J, lerna M, Fraser AR, Stolarski B, McSharry C, Hueber AJ, Baxter D, Hunter J, Gay S, Liew FY, Mclnnes IB: MicroRNA-155 as a proinflammatory regulator in clinical and experimental arthritis. Proc Natl Acad SciU SA 2011, 108:11193-11198.

34. Pauley KM, Satoh M, Chan AL, Bubb MR, Reeves WH, Chan EK: Upregulated miR-146a expression in peripheral blood mononuclear cells from rheumatoid arthritis patients. Arthritis Res Ther 2008, 10:R101.

35. Nakamachi Y, Kawano S, Takenokuchi M, Nishimura K, Sakai Y, Chin T, Saura R, Kurosaka M, Kumagai S: MicroRNA-124a is a key regulator of proliferation and monocyte chemoattractant protein 1 secretion in fibroblast-like synoviocytes from patients with rheumatoid arthritis. Arthritis Rheum 2009, 60:1294-1304

36. Li J, Wan Y, Guo Q, Zou L, Zhang J, Fang Y, Fu X, Liu H, Lu L, Wu Y: Altered microRNA expression profile with miR-146a upregulation in CD4+ T cells from patients with rheumatoid arthritis. Arthritis Res Ther 2010, 12:R81.

37. Nagata Y, Nakasa T, Mochizuki Y, Ishikawa M, Miyaki S, Shibuya H, Yamasaki K, Adachi N, Asahara H, Ochi M: Induction of apoptosis in the synovium of mice with autoantibody-mediated arthritis by the intraarticular injection of double-stranded MicroRNA-15a. Arthritis Rheum 2009, 60:2677-2683.

38. Otaegui D, Baranzini SE, Armañanzas R, Calvo B, Muñoz-Culla M, Khankhanian P. Inza I, Lozano JA, Castillo-Triviño T, Asensio A, Olaskoaga J, López de Munain A: Differential micro RNA expression in PBMC from multiple sclerosis patients. PLoS One 2009, 4:e6309.

39. Lindberg RL, Hoffmann F, Mehling M, Kuhle J, Kappos L: Altered expression of miR-17-5p in CD4+ lymphocytes of relapsing-remitting multiple sclerosis patients. Eur J Immunol 2010, 40:888-898.

40. Junker A, Krumbholz M, Eisele S, Mohan $\mathrm{H}$, Augstein F, Bittner R, Lassmann $\mathrm{H}$ Wekerle $H$, Hohlfeld R, Meinl E: MicroRNA profiling of multiple sclerosis lesions identifies modulators of the regulatory protein CD47. Brain 2009, 132:3342-3352.

41. Dai R, Zhang Y, Khan D, Heid B, Caudell D, Crasta O, Ahmed SA: Identification of a common lupus disease-associated microRNA expression pattern in three different murine models of lupus. PLoS One 2010, 5:e14302.

42. Dai Y, Huang YS, Tang M, Lv TY, Hu CX, Tan YH, Xu ZM, Yin YB: Microarray analysis of microRNA expression in peripheral blood cells of systemic lupus erythematosus patients. Lupus 2007, 16:939-946.

43. O'Connell RM, Taganov KD, Boldin MP, Cheng G, Baltimore D: MicroRNA-155 is induced during the macrophage inflammatory response. Proc Natl Acad SciU SA 2007, 104:1604-1609.

44. Wang G, Tam LS, Kwan BC, Li EK, Chow KM, Luk CC, Li PK, Szeto CC. Expression of miR-146a and miR-155 in the urinary sediment of systemic lupus erythematosus. Clin Rheumatol 2012, 31:435-440.

45. Tang Y, Luo X, Cui H, Ni X, Yuan M, Guo Y, Huang X, Zhou H, de Vries N, Tak PP, Chen S, Shen N: MicroRNA-146A contributes to abnormal activation of the type I interferon pathway in human lupus by targeting the key signaling 
proteins. Arthritis Rheum 2009, 60:1065-1075

46. Pan W, Zhu S, Yuan M, Cui H, Wang L, Luo X, Li J, Zhou H, Tang Y, Shen N: MicroRNA-21 and microRNA-148a contribute to DNA hypomethylation in lupus $C D 4+T$ cells by directly and indirectly targeting DNA methyltransferase 1. J Immunol 2010, 184:6773-6781.

47. Luo X, Yang W, Ye DQ, Cui H, Zhang Y, Hirankarn N, Qian X, Tang Y, Lau YL, de Vries N, Tak PP, Tsao BP, Shen N: A functional variant in microRNA-146a promoter modulates its expression and confers disease risk for systemic lupus erythematosus. PLoS Genet 2011, 7:e1002128.

48. Löfgren SE, Frostegård J, Truedsson L, Pons-Estel BA, D'Alfonso S, Witte T, Lauwerys BR, Endreffy E, Kovács L, Vasconcelos C, Martins da Silva B, Kozyrev SV, Alarcón-Riquelme ME: Genetic association of miRNA-146a with systemic lupus erythematosus in Europeans through decreased expression of the gene. Genes Immun 2012, 13:268-274

49. Wu F, Guo NJ, Tian H, Marohn M, Gearhart S, Bayless TM, Brant SR, Kwon JH: Peripheral blood microRNAs distinguish active ulcerative colitis and Crohn's disease. Inflamm Bowel Dis 2011, 17:241-250.

50. Duttagupta R, DiRienzo S, Jiang R, Bowers J, Gollub J, Kao J, Kearney K, Rudolph D, Dawany NB, Showe MK, Stamato T, Getts RC, Jones KW: Genomewide maps of circulating miRNA biomarkers for ulcerative colitis. PLoS One 2012, 7:e31241

51. Biton M, Levin A, Slyper M, Alkalay I, Horwitz E, Mor H, Kredo-Russo S, AvnitSagi T, Cojocaru G, Zreik F, Bentwich Z, Poy MN, Artis D, Walker MD, Hornstein E, Pikarsky E, Ben-Neriah Y: Epithelial microRNAs regulate gut mucosal immunity via epithelium-T cell crosstalk. Nat Immunol 2011, 12:239-246.

52. Wu F, Zhang S, Dassopoulos T, Harris ML, Bayless TM, Meltzer SJ, Brant SR, Kwon JH: Identification of microRNAs associated with ileal and colonic Crohn's disease. Inflamm Bowel Dis 2010, 16:1729-1738.

53. Fasseu M, Tréton X, Guichard C, Pedruzzi E, Cazals-Hatem D, Richard C, Aparicio T, Daniel F, Soulé JC, Moreau R, Bouhnik Y, Laburthe M, Groyer A, Ogier-Denis E: Identification of restricted subsets of mature microRNA abnormally expressed in inactive colonic mucosa of patients with inflammatory bowel disease. PLoS One 2010, 5:pii: e13160.

54. Olaru AV, Selaru FM, Mori Y, Vazquez C, David S, Paun B, Cheng Y, Jin Z, Yang J, Agarwal R, Abraham JM, Dassopoulos T, Harris M, Bayless TM, Kwon J, Harpaz N, Livak F, Meltzer SJ: Dynamic changes in the expression of MicroRNA-31 during inflammatory bowel disease-associated neoplastic transformation. Inflamm Bowel Dis 2011, 17:221-231.

55. Pauley KM, Stewart CM, Gauna AE, Dupre LC, Kuklani R, Chan AL, Pauley BA, Reeves WH, Chan EK, Cha S: Altered miR-146a expression in Sjogren's syndrome and its functional role in innate immunity. Eur I Immunol 2011, 41:2029-2039

56. Michael A, Bajracharya SD, Yuen PS, Zhou H, Star RA, Illei GG, Alevizos I: Exosomes from human saliva as a source of microRNA biomarkers. Oral Dis 2010, 16:34-38.

57. Alevizos I, Bajracharya S, Alexander S, Turner RJ, Illei GG: MicroRNA profiling of minor salivary glands identifies disease and inflammation biomarkers in Sjögren's syndrome patients. Paper presented at: American College of Rheumatology/Association of Rheumatology Health Professionals Scientific Meeting; 20 Oct. 2009; Philadelphia, PA, USA. Presentation 1961.

58. Xiao C, Srinivasan L, Calado DP, Patterson HC, Zhang B, Wang J, Henderson $J M$, Kutok JL, Rajewsky K: Lymphoproliferative disease and autoimmunity in mice with increased miR-17-92 expression in lymphocytes. Nat Immunol 2008, 9:405-414.

59. Tandon M, Gallo A, Jang SI, Illei GG, Alevizos I: Deep sequencing of short RNAs reveals novel microRNAs in minor salivary glands of patients with Sjogren's syndrome. Oral Dis 2012, 18:127-131.
60. Sonkoly E, Wei T, Janson PC, Sääf A, Lundeberg L, Tengvall-Linder M, Norstedt G, Alenius H, Homey B, Scheynius A, Ståhle M, Pivarcsi A: MicroRNAs: novel regulators involved in the pathogenesis of psoriasis? PLoS One 2007, 2:e610.

61. Meisgen F, Xu N, Wei T, Janson PC, Obad S, Broom O, Nagy N, Kauppinen S, Kemény L, Ståhle M, Pivarcsi A, Sonkoly E: MiR-21 is up-regulated in psoriasis and suppresses T cell apoptosis. Exp Dermatol 2012, 21:312-314.

62. Padgett KA, Lan RY, Leung PC, Lleo A, Dawson K, Pfeiff J, Mao TK, Coppel RL, Ansari AA, Gershwin ME: Primary biliary cirrhosis is associated with altered hepatic microRNA expression. J Autoimmun 2009, 32:246-253.

63. Banales JM, Saez E, Uriz M, Sarvide S, Urribarri AD, Splinter P, Tietz Bogert PS, Bujanda L, Prieto J, Medina JF, LaRusso NF: Up-regulation of microRNA 506 leads to decreased $\mathrm{Cl}-/ \mathrm{HCO}$ - anion exchanger 2 expression in biliary epithelium of patients with primary biliary cirrhosis. Hepatology 2012, 56:687-697.

64. Hezova R, Slaby O, Faltejskova P, Mikulkova Z, Buresova I, Raja KR, Hodek J, Ovesna J, Michalek J: microRNA-342, microRNA-191 and microRNA-510 are differentially expressed in T regulatory cells of type 1 diabetic patients. Cell Immunol 2010, 260:70-74.

65. Sebastiani G, Grieco FA, Spagnuolo I, Galleri L, Cataldo D, Dotta F: Increased expression of microRNA miR-326 in type 1 diabetic patients with ongoing islet autoimmunity. Diabetes Metab Res Rev 2011, 27:862-866.

66. Ruan Q, Wang T, Kameswaran V, Wei Q, Johnson DS, Matschinsky F, Shi W, Chen YH: The microRNA-21-PDCD4 axis prevents type 1 diabetes by blocking pancreatic beta cell death. Proc Natl Acad Sci U S A 2011, 108:12030-12035.

67. Mi QS, He HZ, Dong Z, Isales C, Zhou L: microRNA deficiency in pancreatic islet cells exacerbates streptozotocin-induced murine autoimmune diabetes. Cell Cycle 2010, 9:3127-3129.

68. Stagakis E, Bertsias G, Verginis P, Nakou M, Hatziapostolou M, Kritikos H, Iliopoulos D, Boumpas DT: Identification of novel microRNA signatures linked to human lupus disease activity and pathogenesis: miR-21 regulates aberrant $T$ cell responses through regulation of PDCD4 expression. Ann Rheum Dis 2011, 70:1496-1506.

69. Murugaiyan G, Beynon V, Mittal A, Joller N, Weiner HL: Silencing microRNA-155 ameliorates experimental autoimmune encephalomyelitis. $\mathrm{J}$ Immunol 2011, 187:2213-2221.

70. Babar IA, Cheng CJ, Booth CJ, Liang X, Weidhaas JB, Saltzman WM, Slack FJ: Nanoparticle-based therapy in an in vivo microRNA-155 (miR-155)dependent mouse model of lymphoma. Proc Natl Acad Sci U S A 2012, 109:E1695-1704

71. Haussecker D, Kay MA: miR-122 continues to blaze the trail for microRNA therapeutics. Mol Ther 2010, 18:240-242.

72. van Rooij E, Marshall WS, Olson EN: Toward microRNA-based therapeutics for heart disease: the sense in antisense. Circ Res 2008, 103:919-928.

73. Heneghan HM, Miller N, Kerin MJ: MiRNAs as biomarkers and therapeutic targets in cancer. Curr Opin Pharmacol 2010, 10:543-550.

\section{doi:10.1186/ar4131}

Cite this article as: Hu R, O'Connell RM: MicroRNA control in the development of systemic autoimmunity. Arthritis Research \& Therapy 2013, 15:202. 